\title{
Human milk blocks DC-SIGN-pathogen interaction via MUC1
}

\section{Nathalie Koning ${ }^{1}$, Sabine F. M. Kessen ${ }^{1}$, J. Patrick Van Der Voorn' ${ }^{2}$, Ben J. Appelmelk ${ }^{3}$, Prescilla V. Jeurink ${ }^{4,5}$, Leon M. J. Knippels ${ }^{4,5}$, Johan Garssen ${ }^{4,5}$ and Yvette Van Kooyk ${ }^{1 *}$}

1 Department of Molecular Cell Biology and Immunology, VU University Medical Center, Amsterdam, Netherlands

${ }^{2}$ Department of Pathology, VU University Medical Center, Amsterdam, Netherlands

${ }^{3}$ Department of Medical Microbiology and Infection Control, VU University Medical Center, Amsterdam, Netherlands

${ }_{4}^{4}$ Immunology, Danone Research - Centre for Specialised Nutrition, Wageningen, Netherlands

${ }^{5}$ Faculty of Science, Utrecht Institute for Pharmaceutical Sciences, University Utrecht, Utrecht, Netherlands

\section{Edited by:}

Lorraine M. Sordillo, Michigan State

University, USA

\section{Reviewed by:}

Luisa Martinez-Pomares, University of Nottingham, UK

Geanncarlo Lugo-Villarino, Centre

National de la Recherche Scientifique (CNRS), France

\section{*Correspondence:}

Yvette Van Kooyk, Department of Molecular Cell biology and

Immunology, VU University Medical

Centre, v.d. Boechorststraat 7, 1081

BT Amsterdam, Netherlands

e-mail:y.vankooyk@vumc.nl
Beneficial effects of breastfeeding are well-recognized and include both immediate neonatal protection against pathogens and long-term protection against allergies and autoimmune diseases. Although several proteins have been identified to have anti-viral or anti-bacterial effects like secretory IgA or lactoferrin, the mechanisms of immune modulation are not fully understood. Recent studies identified important beneficial effects of glycans in human milk, such as those expressed in oligosaccharides or on glycoproteins. Glycans are recognized by the carbohydrate receptors C-type lectins on dendritic cell (DC) and specific tissue macrophages, which exert important functions in immune modulation and immune homeostasis. A well-characterized C-type lectin is dendritic cell-specific intercellular adhesion molecule-3-grabbing non-integrin (DC-SIGN), which binds terminal fucose. The present study shows that in human milk, MUC1 is the major milk glycoprotein that binds to the lectin domain of DC-SIGN and prevents pathogen interaction through the presence of Lewis x-type oligosaccharides. Surprisingly, this was specific for human milk, as formula, bovine or camel milk did not show any presence of proteins that interacted with DC-SIGN. The expression of DC-SIGN is found in young infants along the entire gastrointestinal tract. Our data thus suggest the importance of human milk glycoproteins for blocking pathogen interaction to DC in young children. Moreover, a potential benefit of human milk later in life in shaping the infants immune system through DC-SIGN cannot be ruled out.

Keywords: DC-SIGN, human milk, immune modulation, intestine, mucin

\section{INTRODUCTION}

Inflammatory diseases like allergies and autoimmune diseases are increasing in the Western world. These disorders are associated with a disturbed immune balance, feeding the necessity to unravel mechanisms of immune tolerance induction, specifically early in life. For years, it is known that breastfeeding has beneficial effects for infants at young age, for example, by strongly reducing the mortality rate from infections by common pathogens. Moreover, breastfed individuals showed, although with controversies, a lower risk of developing allergies and autoimmune disorders such as type 1 diabetes, Crohn's disease, and juvenile rheumatoid arthritis later in life (1-4). For a long time, protection against pathogens was attributed to secretory IgA, which could capture pathogens from the gastrointestinal system of the child. Later, also milk components were identified as possible immune modulators. For example, the major milk protein lactoferrin is well known for its anti-viral and anti-bactericidal activity (5), and similar effects have been described for lysozyme (6). Other immunologically interesting components of human milk include growth hormones, cytokines, and glycans.

Glycans in human milk are abundantly present in oligosaccharides or on glycoproteins. These glycans may play an important role in protective immunity in young children. It has been demonstrated that the incidence of diarrhea caused by different pathogens is inversely related to the type and amount of fucose-type glycans in human milk that the infants received $(7,8)$. Interestingly, high concentrations of such glycans were also significantly associated with a lower incidence of respiratory disease in children (9), suggesting beneficial systemic effects as well.

Glycans are recognized by C-type lectins expressed mostly by myeloid antigen presenting cells such as macrophages and dendritic cells (DCs). C-type lectins are carbohydrate receptors that bind a variety of glycan moieties in a calcium-dependent manner. They belong to the family of antigen uptake receptors, as they recognize cell surface glycans on many viruses, bacteria, and parasites, but may bind and respond to glycans on self-proteins as well. A well-characterized C-type lectin on DCs is dendritic cellspecific intercellular adhesion molecule-3-grabbing non-integrin (DC-SIGN). Ligands for DC-SIGN include fucosylated structures, like the Lewis antigens, as well as mannosylated moieties. As antigen uptake receptor, DC-SIGN shuttles antigen in the intracellular compartments of DCs to load antigen on MHC class I and II molecules to stimulate antigen-specific CD8 and CD4 T cell responses, respectively $(10-13)$. On the other hand, DC-SIGN 
recognizes a wide variety of pathogens that is not necessarily presented to $\mathrm{T}$ cells but rather modulates immune responses. For example, DC-SIGN signaling following binding to Mycobacterium tuberculosis, Borrelia burgdorferi, or HIV results in immune inhibition through Raf- 1 activation, prolonged Nf- $\kappa \mathrm{B}$ activation, high IL-10 production, or decreased expression of proinflammatory cytokines (14-16). The diversity of DC-SIGN actions was further shown by its ability to promote either Th1 or Th2 responses, dependent on the phase variant of Helicobacter pylori (17). Also, probiotics have been reported to interact with DC-SIGN, which instead resulted in the induction of regulatory $\mathrm{T}$ cell responses (18). In the case of a pathogen interacting with DC-SIGN, the simultaneously triggering of specific toll-like receptors (TLR), and the interplay between DC-SIGN and TLR signaling is important in the differential outcome of the immune response. DC-SIGN is thus an innate signaling receptor that dependent on the type of glycan it interacts with (mannose or fucose) interferes with TLR signaling (19). Based on its specificity for self-glycosylated proteins, such as CEA, MUC1, MUC6, butyrophilin, DC-SIGN has been considered important for maintenance of immune homeostasis (20).

The contributions of the gastrointestinal tract in shaping immunity are undeniable. Mucus layers, anti-bacterial proteins, and numerous amounts of microbial communities, termed the microbiota, all cooperate in protecting the host while providing metabolic benefits, as excellently reviewed by Hooper et al. (21). Importantly, DCs are localized in all areas of the gastrointestinal tract. Equipped with C-type lectins and other molecules for recognizing, internalizing, and presenting antigens, DCs are the primary cells to initiate various immune responses, including anergy. Despite all indications that abundant glycans in human milk provide important benefits to the infant, underlying biological mechanisms have not yet been addressed. Therefore, we aimed to study the interaction of human milk with C-type lectins on DCs. In adults, DC-SIGN is expressed on a subpopulation of DCs in the intestinal mucosa $(22,23)$. However, information on DC-SIGN expression in the gastrointestinal tract of neonates is scarce. Data from the present study show that human milk strongly interacts with DCs through DC-SIGN expressed in the entire gastrointestinal tract of young infants. Furthermore, our data suggest that this interaction is dependent on Lewis $\mathrm{x}$ present on the glycoprotein mucin 1 (MUC1). We demonstrate this to be a potent mechanism in blocking pathogen interaction with DCs and suggest this to be an important mechanism of the capability of human milk to modulate the infant's immunity, presumably with long-term health benefits.

\section{MATERIALS AND METHODS \\ MILK SAMPLES}

Human milk from 40 mothers was provided by the European Milk Bank Association (EMBA, Milan, Italy). Human milk samples, as well as bovine milk (Campina, The Netherlands), formula milk (Nutricia Nutrilon 1, Danone, reconstituted according to the manufacturers instructions), and camel milk (camel farm Smits, Berlicum, The Netherlands) were skimmed by obtaining the aqueous phase after three consecutive rounds of centrifugation at $680 \times g$ for $10 \mathrm{~min}$ at $4^{\circ} \mathrm{C}$. The samples were stored at $-80^{\circ} \mathrm{C}$. For use in cell culture experiments, skimmed milk samples were filter-sterilized. To fractionate human milk, the aqueous layer $(50 \mathrm{ml})$ was freeze-dried overnight and dissolved in $15 \mathrm{ml}$ water, mixed with $15 \mathrm{ml} \mathrm{N}$-butanol and $30 \mathrm{ml}$ di-isopropyl ether and incubated at $4^{\circ} \mathrm{C}$ for $2 \mathrm{~h}$, rolling. After centrifugation, the upper (organic) layer was removed and aqueous layer mixed again with $30 \mathrm{ml}$ di-isopropyl ether for $2 \mathrm{~h}$ incubation at $4^{\circ} \mathrm{C}$. After centrifugation, the aqueous layer was collected and freeze-dried overnight. Twenty milliliters of PBS were added and proteins were solubilized for $1 \mathrm{~h}$ by sonication and filtered through a $0.45 \mu \mathrm{m}$ filter. Finally, milk proteins were separated on a gel filtration column [Sepharose $6(10 \times 300)$, GE Healthcare Europe].

\section{REAGENTS}

Recombinant DC-SIGN and MGL proteins consisted of the extracellular region (containing the carbohydrate recognition domain) fused with an immunoglobulin Fc tail for detection in ELISA and were produced by $293 \mathrm{~T}$ cells as described previously (24). The DC-SIGN blocking antibody AZN-D1 and 1G6.6 antibody for MGL were purified from hybridoma supernatant using a protein A sepharose FF column (Amersham). Lactoferrin isolated from human milk was obtained from Sigma-Aldrich. MUC1 was detected by clone 214D4 (provided by John Hilkens, Netherlands Cancer Institute, Amsterdam) specifically recognizing the amino acid sequence PDTR in the extracellular domain of MUC1 (glycosylation independent) and was biotinylated using a biotinylation kit (Pierce). MUC4 was detected by clone 8G7, $\kappa$-casein by clone A-14 (Santa Cruz Biotechnology, Inc.), $\alpha$-lactalbumin by clone F20.16 (Novus Biologicals), Lewis x by clone P12 and Lewis y by clone F3 (Calbiochem), CD83-PE by clone L307.4, CD86-PE by clone 2331, HLA-DR-PE by clone L243 (BD Pharmingen), and DC-SIGN by clone DC-28 (gift of R. Doms, University of Pennsylvania, Philadelphia, PA, USA).

\section{ELISA}

Maxisorp ELISA plates (NUNC) were either coated directly with skimmed milk or fractionated milk samples (in 1:10 dilution, unless stated otherwise) in $0.2 \mathrm{M} \mathrm{NaHCO}_{3}$ buffer overnight at $4^{\circ} \mathrm{C}$, or in case of human milk protein capturing ELISA, with purified lactoferrin $(100 \mathrm{ng} / \mathrm{ml})$ or with antibodies to MUC1 (unbiotinylated, $3 \mu \mathrm{g} / \mathrm{ml})$, MUC4 $(40 \mu \mathrm{g} / \mathrm{ml})$, $\kappa$-casein $(20 \mu \mathrm{g} / \mathrm{ml})$, or $\alpha$-lactalbumin $(30 \mu \mathrm{g} / \mathrm{ml})$. The plates were blocked in Tris-sodium buffer containing $1 \%$ BSA, followed by incubation with skimmed human milk in case of milk protein capture. For C-type lectin binding, plates were washed in Tris-sodium-0.05\%Tween and incubated with DC-SIGN-Fc or MGL-Fc for $1 \mathrm{~h}$ at room temperature (RT). For MUC1 detection, plates were incubated with biotinylated MUC1 antibody $(2 \mu \mathrm{g} / \mathrm{ml})$. To detect Lewis-antigen expression following MUC1 capture, plates were incubated with antibodies to Lewis $\mathrm{x}$ or Lewis y $(0.5 \mu \mathrm{g} / \mathrm{ml})$. After washing, binding of C-type lectins was detected by PO-labeled goat anti-human IgG, binding of MUC1 by PO-labeled streptavidin and binding of Lewis antigens by PO-labeled goat anti-mouse IgM (Jackson Immunoresearch). The reaction was visualized in $100 \mu \mathrm{g} / \mathrm{ml}$ $3,3^{\prime}-5,5^{\prime}$-tetramethylbenzidine (TMB) substrate (Sigma-Aldrich) and optical density was measured by a microplate absorbance spectrophotometer (Biorad) at $450 \mathrm{~nm}$. 


\section{CELLS}

Human immature DCs were generated from monocytes isolated from buffy coats of healthy donors (Sanquin, Amsterdam, The Netherlands) by culturing the cells for 4-5 days in RPMI 1640 medium (Invitrogen) containing 10\% fetal calf serum and in the presence of IL- 4 and GM-CSF (500 and $800 \mathrm{U} / \mathrm{ml}$, respectively, Biosource). Monocyte-derived DCs were matured in the presence of LPS (10 ng/ml, Sigma-Aldrich) for $24 \mathrm{~h}$ and co-incubated with sterilized human milk (1:10 dilution) and AZN-D1 $(20 \mu \mathrm{g} / \mathrm{ml})$. Next, cells were either washed and incubated with indicated antibodies for detection in flow cytometry and analyzed using FlowJo Software, or were used for quantitative PCR.

\section{CELL ADHESION ASSAY}

Nunc-Immuno Maxisorp plates were coated with milk (1:10 dilution unless stated otherwise) in $\mathrm{NaHCO}_{3}$ buffer $(0.2 \mathrm{M}) \mathrm{o} / \mathrm{n}$ at $4{ }^{\circ} \mathrm{C}$. After washing and blocking the NUNC plate in TSM/BSA (1\%), DCs labeled with Calcein-AM (Molecular Probes) were added in the presence or absence of the calcium chelator EGTA $(10 \mathrm{mM})$, AZN-D1 $(20 \mu \mathrm{g} / \mathrm{ml})$, or $1 \mathrm{G} 6.6(20 \mu \mathrm{g} / \mathrm{ml})$ and incubated for $90 \mathrm{~min}$ at $37^{\circ} \mathrm{C}$. The non-adherent cells were gently washed away and the adherent cells were lysed in $50 \mathrm{mM}$ Tris-HCL/0.1\%SDS. Fluorescence was quantified on a Fluostar spectrofluorimeter (BMG Labtech) at $485 / 520 \mathrm{~nm}$.

\section{BACTERIA BLOCKING ASSAY}

Dendritic cells $\left(1 \times 10^{5}\right.$ cells/well $)$ were incubated with filtersterilized milk (1:10 dilution), AZN-D1 $(10 \mu \mathrm{g} / \mathrm{ml}), 1 \mathrm{~g} 6.6$ $(10 \mu \mathrm{g} / \mathrm{ml})$, or Tris-sodium buffer alone for $45 \mathrm{~min}$ at $37^{\circ} \mathrm{C}$. FITClabeled DC-SIGN binding variant of Neisseria gonorrhoeae (25) or FITC-labeled H. pylori (phase variants J223.3 and J223.8) (17) were co-incubated with the DCs in a 25:1 (bacteria:DC) ratio for another $45 \mathrm{~min}$ at $4^{\circ} \mathrm{C}$. Cells were washed in Tris-sodium buffer and FITC-positive DCs were quantified using a flow cytometer (Facscan, BD) and FlowJo Software (Tree Star, Inc.).

\section{QUANTITATIVE PCR}

Cells were lysed for RNA isolation (mRNA capture kit, Roche) and cDNA synthesis (Reverse Transcription System, Promega), according to manufacturers instructions, after which the cDNA was stored in $-20^{\circ} \mathrm{C}$ until further use. PCR reactions were performed with the SYBR Green method in an ABI 7900HT sequence detection system (Applied Biosystems, USA). Primer sets to the following human target genes were used: IL-10 (fw: $5^{\prime}$-gaggctacggc gctgtcat- $3^{\prime}$, rv: $5^{\prime}$-ccacggecttgctcttgtt- $3^{\prime}$ ), TNF (fw: $5^{\prime}$-tctcgaaccc cgagtgaca- $3^{\prime}$, rv: $5^{\prime}$-tgaggtacaggccctctgatg- $3^{\prime}$ ), IL-6 (fw: $5^{\prime}$-tgcaataa ccaccctgacc- $3^{\prime}$, rv: $5^{\prime}$-tgcgcagaatgagatgagttg- $3^{\prime}$ ), IL-12p35 (fw: $5^{\prime}$ ccactccagaccaggaatgt- $3^{\prime}$, rv: $5^{\prime}$-gcaggtttgggagtggtga- $\left.3^{\prime}\right)$, and IL23 p19 (fw: $5^{\prime}$-gcttgcaaaggatccacca-3', rv: $5^{\prime}$-tccgatcctagcagcttct ca- $\left.3^{\prime}\right)$. Expression of the target gene was normalized to GAPDH (fw: $5^{\prime}$-ccatgttcgtcatgggtgtg- $3^{\prime}$, rv: $5^{\prime}$-ggtgctaagcagttggtggtg- $3^{\prime}$ ), based on a protocol for the definition of the optimal endogenous reference gene (26).

\section{IMMUNOHISTOCHEMISTRY}

Paraffin embedded sections of stomach, duodenum, ileum, colon, and rectum were derived from biopsies (taken for reasons such as diarrhea, suspicion of celiac disease or Hirschsprung's disease) or resections (of congenital malformations, such as atresia) from three different infants per anatomical region. The average age was 6.5 months (range: 1 week-17 months). Material was obtained with informed consent and has been approved by the Ethical Committee VU University Medical Center (Amsterdam, The Netherlands) Biobank Unit Pathology BUP2012-24. The absence of tissue abnormalities was confirmed by a clinical pathologist $(\mathrm{JPvdV})$. Sections were deparaffinized and hydrated in a xylene to alcohol to distilled water series, followed by heat-induced epitope retrieval in sodium-citrate buffer ( $\mathrm{pH} 7.6)$. Endogeneous peroxidase was blocked in blocking buffer (DAKO EnVision). Sections were incubated in 10\% normal goat serum before incubating with anti-DC-SIGN antibody (DC-28) for $1 \mathrm{~h}$ RT. Next, sections were incubated with HRP-labeled secondary antibody (DAKO EnVision) and staining was visualized with DAB (DAKO EnVision). Sections were counterstained with hematoxylin, dehydrated, and mounted in Entallan. All washing steps between incubations were performed in TSM/0.05\% Tween.

\section{STATISTICAL ANALYSIS}

Data were analyzed for significance by one-way analysis of variance and Spearman's correlation test, using GraphPad Prism software (version 5.01). Only $p$-values $<0.05$ were considered significant.

\section{RESULTS}

\section{HUMAN MILK BINDS DC-SIGN ON DCs}

To establish the presence of DC-SIGN binding glycoproteins in human milk, interaction of human milk with DCs was tested in a cell adhesion assay. DCs strongly attached to coated human milk, and to a lesser extent to coated bovine, camel, or formula milk (Figure 1A). Because glycoproteins are abundantly present in human milk, we hypothesized that binding is mediated by glycan receptors, i.e., C-type lectins. Using Fc constructs, we indeed show that human milk strongly interacted with DC-SIGN-Fc, but not to MGL-Fc. In contrast, bovine, camel, and formula milk bound to MGL-Fc, but not to DC-SIGN-Fc (Figure 1B). No differences in Ctype lectin binding were observed between unskimmed, skimmed, and sterilized milk samples (data not shown). A cell adhesion assay confirmed that the strong binding of human milk with DCs was DC-SIGN dependent, because binding was completely blocked by a DC-SIGN blocking antibody, whereas blocking MGL had no effect (Figure 1C). These data show that human milk specifically interacts with DCs via DC-SIGN.

\section{LEWIS x ON MUC1 IN HUMAN MILK BINDS DC-SIGN}

Different milk proteins were tested for their ability to bind DCSIGN. Antibodies to the milk proteins mucin 1 (MUC1), MUC4, $\alpha$-lactalbumin, and $\kappa$-casein were coated on plates to capture the proteins from human milk. Lactoferrin was used as purified protein. MUC1 was the only milk protein showing potent DC-SIGN binding (Figure 2A). Next, human milk was fractionated into 30 fractions, based on protein size, after which we determined the presence of MUC1 as well as the amount of DC-SIGN binding in these fractions. A strong positive correlation between the level of MUC1 and the capacity to bind DC-SIGN $(r=0.8, p<0.0001$, Figure 2B) suggests that MUC1 is a major human milk component binding to DC-SIGN. 

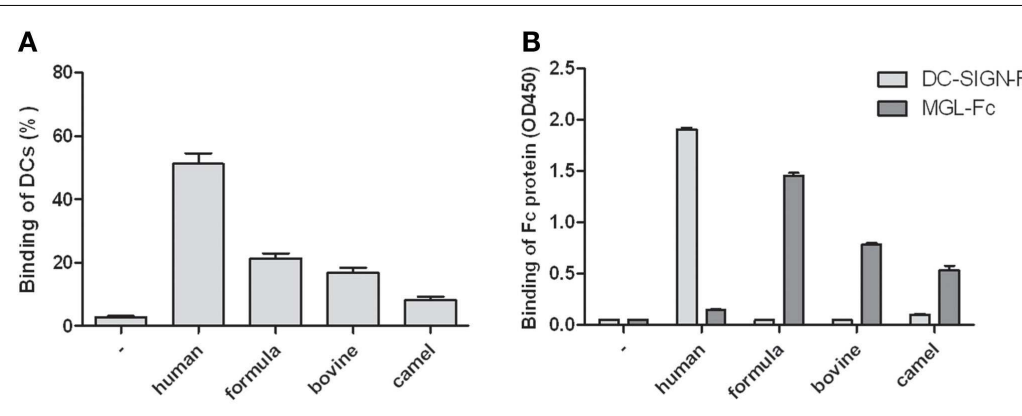

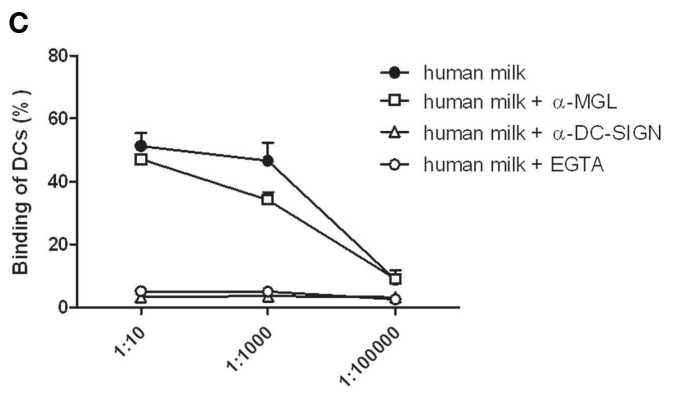

FIGURE 1 | (A) Binding of monocyte-derived dendritic cells to skimmed human, formula, bovine, or camel milk. (B) Binding of skimmed milk to DC-SIGN-Fc or MGL-Fc. (C) Binding of monocyte-derived dendritic cells to skimmed human milk in different dilutions in the presence of EGTA, DC-SIGN blocking antibody AZN-D1, or MGL blocking antibody 1G6.6. Three independent experiments were performed. Data are indicated as mean $\pm S D$.
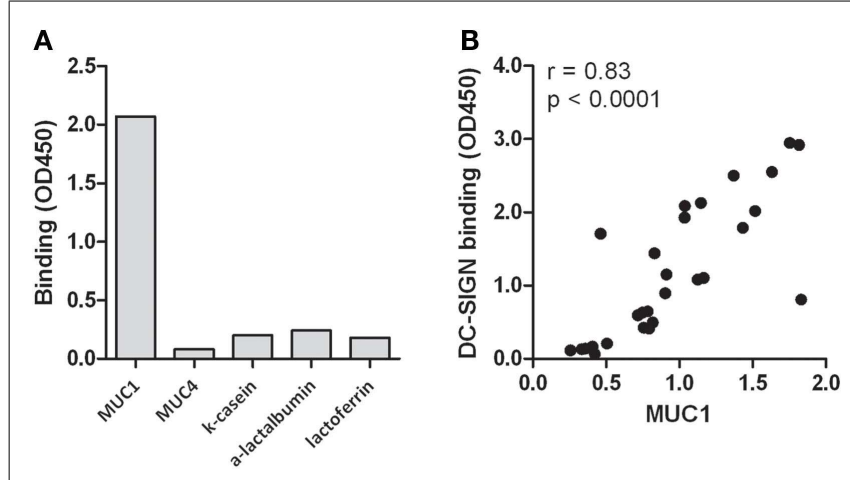

C
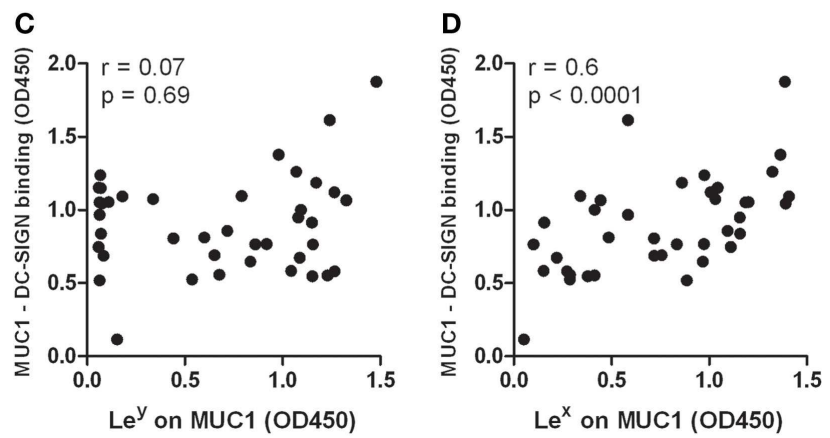

FIGURE 2 | (A) Binding of milk proteins to DC-SIGN. MUC1, MUC4, $\kappa$-casein, and $\alpha$-lactalbumin were captured from human milk using antibodies, whereas lactoferrin was used in purified form. One representative experiment out of three is presented. (B) Correlation of MUC1 levels with DC-SIGN binding in fractionated human milk. Human milk was fractionated into 30 fractions, based on protein size. MUC1 levels and DC-SIGN binding was tested in ELISA. (C) Correlation of Lewis $x$ levels on MUC1 in 40 milk donors with the capacity of captured MUC1 binding to DC-SIGN. (D) Correlation of Lewis y levels on MUC1 in 40 milk donors with the capacity of captured MUC1 binding to DC-SIGN. Typical experiment out of two is presented.

Next, we analyzed well-known ligands for DC-SIGN, Lewis $\mathrm{x}$, and Lewis y, on MUC1 in milk samples derived from 40 milk donors. Both Lewis $\mathrm{x}$ and $\mathrm{y}$ could be detected on MUC1, but expression levels are donor-dependent. Interestingly, levels of Lewis $\mathrm{x}$ on MUC1 positively correlated with binding of MUC1 to DC-SIGN ( $r=0.6, p<0.0001$, Figure $2 \mathrm{C}$ ), but Lewis y levels on MUC1 did not ( $r=0.07, p=0.69$, Figure 2D). Importantly, no correlation was found between the level of Lewis antigens and the level of MUC1 in these samples (Lewis $\mathrm{x}: r=0.27, p=0.1$; Lewis y: $r=0.03, p=0.8$ ), indicating that higher MUC1 levels do not inevitably contain higher Lewis antigen levels and thus reflects individual variability in Lewis antigen expression. These data therefore strongly suggest that human milk binds DC-SIGN via Lewis $\mathrm{x}$ on MUC1.

\section{INTERACTION OF HUMAN MILK WITH DC-SIGN DOES NOT AFFECT DC IMMUNE RESPONSES}

DC-SIGN triggering has been described to modulate immune responses (14). We therefore studied the effect of milk-DC-SIGN interaction on DC-mediated responses. Although LPS activated DCs incubated with human milk showed upregulation of IL-10 mRNA and protein levels, this was not attributed to DC-SIGN as blocking DC-SIGN did not inhibit IL-10 induction (Figure 3A). Similar results were obtained for TNF (data not shown). Human milk did not affect the expression of IL-6, IL-12p35, and IL23p19 (data not shown). Furthermore, human milk did neither induce DC maturation nor affected LPS-mediated DC maturation (Figure 3B) or T cell proliferation (data not shown).

\section{MUC1 IN HUMAN MILK BLOCKS PATHOGEN INTERACTIONS WITH DCS}

We hypothesized that the abundantly present glycoproteins in human milk may have protective properties by preventing pathogen interactions with DCs. To test this hypothesis, we incubated DCs with the DC-SIGN binding variant of N. gonorrhoeae. Binding of $N$. gonorrhoeae was inhibited in the presence of a blocking DC-SIGN antibody, but not when MGL was blocked (Figure 4A). Interestingly, human milk inhibited $N$. gonorrhoeae binding to DCs to a similar extent as the DC-SIGN blocking antibody. As expected, formula milk, which does not bind to DC-SIGN but rather binds MGL (Figure 1B), had no effect on bacteria binding. Because human milk binding to DC-SIGN is dependent on Lewis $\mathrm{x}$ on MUC1 (Figure 2), we incubated DCs with $N$. gonorrhoeae in the presence of fractionated milk samples containing different amounts of MUC1. Indeed, the fractions that inhibited bacteria binding to DCs (Fraction C4, C6, and C8, Figure 4B), showed strongest DC-SIGN binding in ELISA (Figure 4C), contained highest levels of MUC1 (Figure 4D) as well as the highest 
A

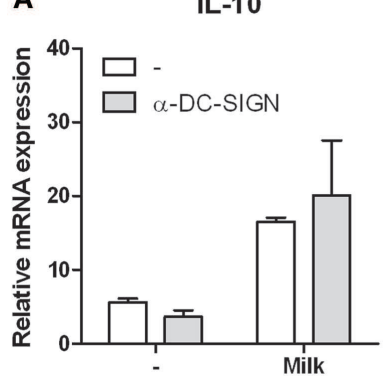

B

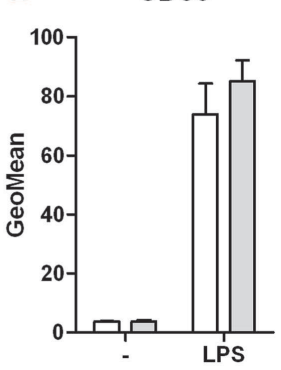

CD86

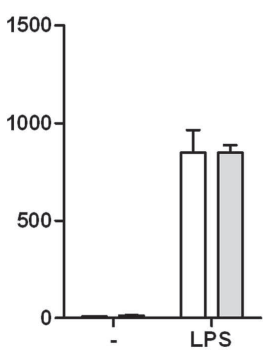

HLA-DR

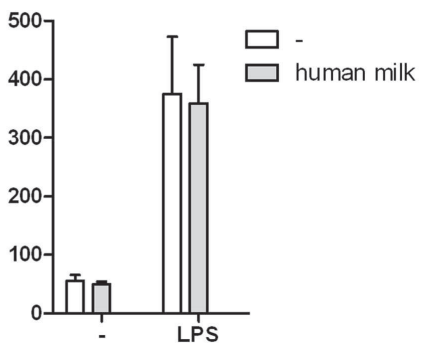

FIGURE 3 | (A) IL-10 expression in human monocyte-derived dendritic cells incubated in human milk with and without the blocking DC-SIGN antibody AZN-D1. Expression is normalized to GAPDH. (B) Cell surface expression of the maturation markers CD83, CD86, and HLA-DR on human monocyte-derived dendritic cells following incubation with human milk and after LPS stimulation. Data are indicated as mean \pm SD of three experiments performed. amount of Lewis $\mathrm{x}$ present on MUC1 (Figure 4E), reflected in a highly significant negative correlation between the percentage of bacteria-positive cells and the levels of MUC1 (Figure 4F). To see whether these observations also apply to a relevant gastrointestinal pathogen, we tested the gastrointestinal pathogen H. pylori. We used two phase variants of $H$. pylori that were previously shown to bind differentially to DC-SIGN (17). We confirmed that phase variant J223.3 binds to DC-SIGN but phase variant J223.8 does not (Figure 4G), as a result of the lack of Lewis y and $\mathrm{x}$ (17). In a competition assay, we further demonstrate that J223.3 binding to DC-SIGN was inhibited by the negative controls mannan and the calcium chelator EGTA and by human milk in a dose dependent manner (Figure 4H). Like shown for N. gonorrhoeae, human milk also blocks $H$. pylori J223.3 binding to DCs to a similar extent as the DC-SIGN blocking antibody, and, in line with Figure 4A, anti-MGL or formula milk did not affect bacteria binding to DCs (Figure 4I). A strong and significant negative correlation between J223.3-positive DCs and MUC1 levels demonstrates that MUC1 potently inhibits bacteria binding to DCs (Figure 4J).

\section{DC-SIGN EXPRESSION IN INTESTINAL TRACT OF YOUNG INFANTS}

To investigate the expression of DC-SIGN in the gastrointestinal tract of young infants, we set out to stain various tissues obtained from young infant. Irregular shaped DC-SIGN positive cells were detected in the lamina propria of the stomach, duodenum, ileum, and colon (Figure 5). Expression, however, was not uniform, with each anatomical position containing areas with both high and low numbers of DC-SIGN positive cells. In addition, strong DC-SIGN expression was observed on cells in the submucosa of the ileum and colon, like reported previously in adult tissue (22). The DC-SIGN positive cells in the submucosa had an irregular shaped morphology consistent with DCs, and some cells were in close vicinity of blood vessels.

\section{DISCUSSION}

A wide spectrum of biologically active agents present in human milk extensively promotes the development of the neonatal immature intestine and immune system. The beneficial effects include maturation of the gut barrier, favorable colonization by probiotics, development of tolerance, and thereby related protection against allergies and autoimmune disorders later in life and immediate protection against different pathogens early in life. In the present study, we show how the heavily glycosylated protein MUC1 in human milk prevents pathogen interaction via Lewis $\mathrm{x}$ interaction with DC-SIGN, which is expressed on DCs throughout the gastrointestinal tract of young infants. Because C-type lectins are vital in immune modulation and in the maintenance of immune homeostasis, these data provide further clues for potential mechanisms for proper maturation and tolerization of the neonatal immune system.

In the adult human gastrointestinal tract, DCs are located in the submucosa and in the lamina propria, where they can form protrusions to sample antigens from the gut lumen (27). Several DC subsets with their own ontogeny have been identified $(22,28)$, however, data on the presence and type of DCs in the infants' intestines are very scarce. Here, we identified DC-SIGN expressing cells in the lamina propria of the stomach, duodenum, ileum, colon, and rectum as well as in the submucosa of the ileum, colon, and rectum of young infants. These data are in line with DC-SIGN expression previously found in the lamina propria and associated lymphoid aggregates in fetal tissue (29). DC-SIGN, like most C-type lectins, act as antigen receptors that are able to capture and internalize glycosylated self and foreign antigens from the micro-environment. Although we did not observe a direct DC-SIGN-mediated effect on DC cytokine production or maturation in this study, DC-SIGN is considered important in tolerance induction and maintenance of immune homeostasis by modifying T cell responses $(14,20)$. Interestingly, mouse studies demonstrate that antigen exposure via maternal milk prevents the development of allergic asthma (30-32). Because of the presence of DC-SIGN in the infant's intestine and its immunomodulatory capacity, we speculate an important role for DC-SIGN in capturing antigens from human milk, thereby inducing tolerance. In fact, it has been shown that the mouse homolog of DC-SIGN, SIGNR1, conditions the mucosal immune system to reduce the anaphylactic response triggered by food allergens (33). In addition, also different species of probiotic lactobacilli drive the development of regulatory T cells via specific DC-SIGN interaction (18). Conclusively, these data support an important role for DC-SIGN in the proper development of the neonatal immune system.

Whereas binding of antigens and probiotics in the intestine is important for the induction of tolerance, human milk further 


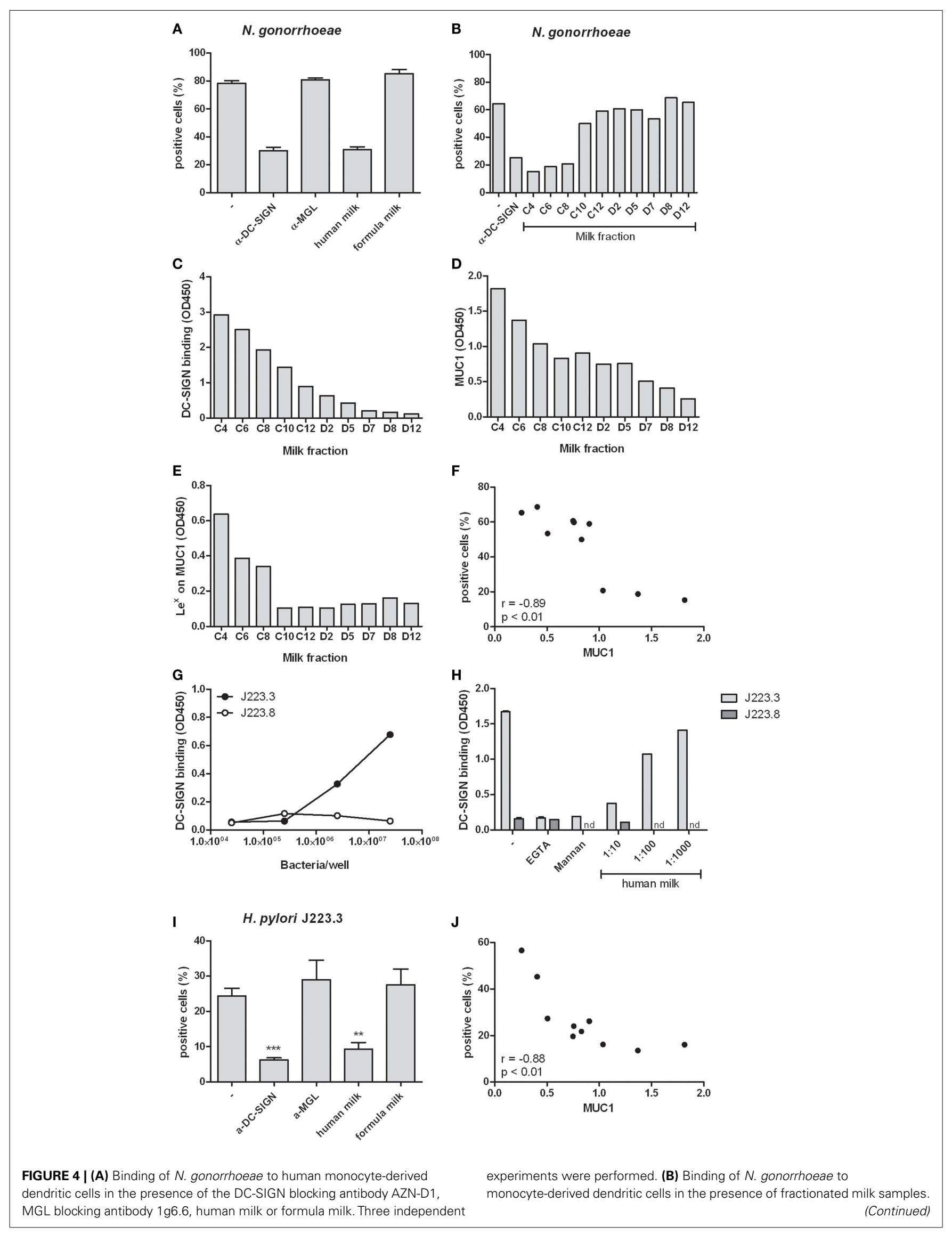




\section{FIGURE 4 | Continued}

(C) DC-SIGN binding capacity of fractionated milk samples in ELISA.

(D) MUC1 levels in fractionated milk samples detected by ELISA.

(E) Lewis $x$ expression on MUC1 captured from fractionated milk samples in ELISA. (F) Correlation of MUC1 levels in fractionated milk samples and the capacity of these samples to inhibit $N$. gonorrhoeae binding to monocyte-derived dendritic cells. (G) Binding of phase variants J223.3 and J223.8 from H. pylori to DC-SIGN-Fc in ELISA.
(H) Binding of $H$. pylori phase variants to DC-SIGN-Fc in the presence of the calcium chelator EGTA, the DC-SIGN ligand mannan and human milk. (I) Binding of $H$. pylori phase variant J223.3 to monocyte-derived dendritic cells in the presence of anti- DC-SIGN or anti-MGL antibody, human or formula milk. (J) Correlation of MUC1 levels in fractionated milk samples and the capacity of these samples to inhibit $H$. pylori J223.3 binding to monocyte-derived dendritic cells. Data are indicated as mean \pm SD of three experiments performed.
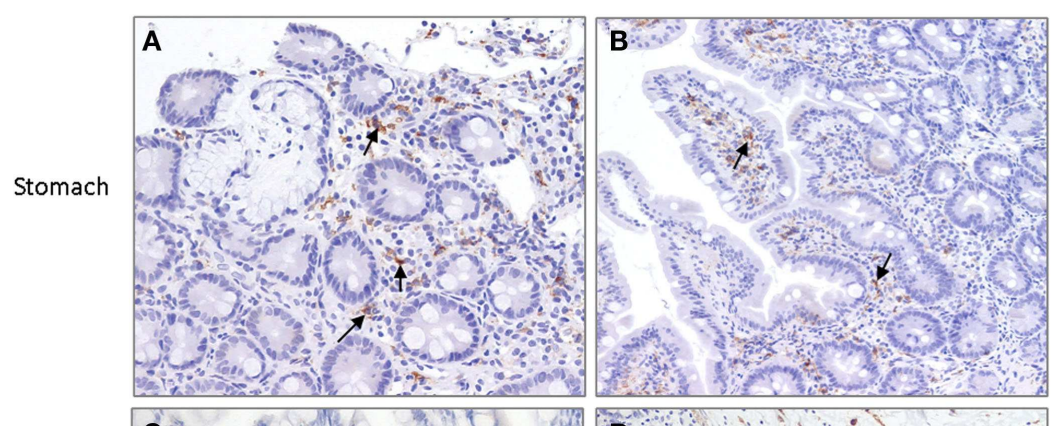

Duodenum
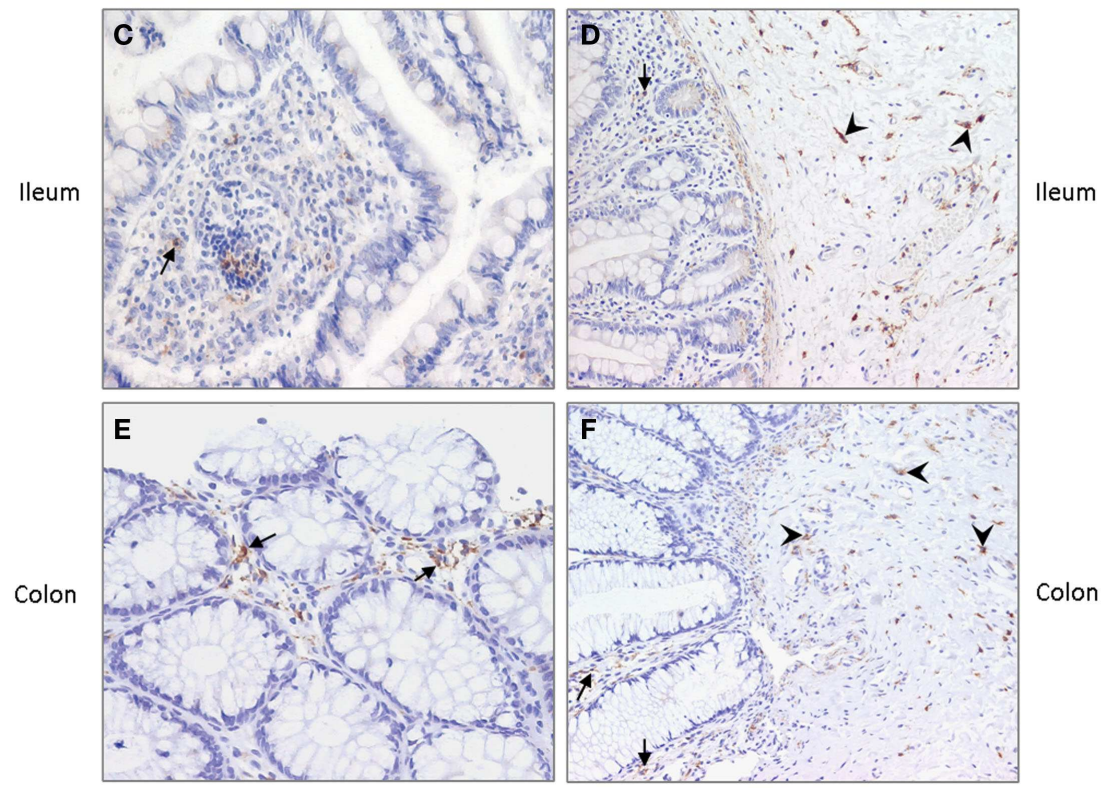

FIGURE 5 | DC-SIGN expression in (A) stomach, (B) duodenum, (C,D) ileum, and (E,F) colon of young infants. Arrows indicate DC-SIGN positive cells in the lamina propria and arrowheads point to positive cells in the submucosa. Nuclei are stained in blue. Magnification $\times 20$.

protects the neonate by preventing interaction with pathogens like Salmonella, Shigella, Vibrio cholerae, Escherichia coli, polioviruses, rotavirus, and respiratory syncytial virus (RSV) (34). We here show that MUC1 is a major milk protein preventing the interaction of bacteria with DC-SIGN on DCs, via Lewis $\mathrm{x}$, but not Lewis y moieties. As this effect was observed for two different and unrelated bacteria, it is highly likely that this mechanism applies to other DCSIGN binding bacteria as well. Importantly, in our earlier work, we have demonstrated that fucosylated milk components, and in particular MUC1 interacted with DC-SIGN and was shown to inhibit DC-mediated transfer of HIV-1 (35-37). In addition to MUC1, also $\kappa$-casein inhibits adhesion of $H$. pylori to human gastric mucosa (38), but our data indicate that $\kappa$-casein does not interact with DC-SIGN. Indeed, inhibition of Streptococcus pneumoniae and $H$. influenzae binding to airway epithelium by $\kappa$-casein seemed rather to depend on GlcNAc containing saccharides (39). Other milk proteins that via a diversity of mechanisms have demonstrated potent protective effects include bile-salt-stimulated lipase (BSSL) (40), soluble CD14 (41), immunoglobulins (42), lsyozyme (6), and lactoferrin (5). Taken together, these milk proteins may exert their protective effects alone, but it is more likely that they act in synergy, where the current findings suggest MUC1-DCSIGN interaction as a significant mechanism in this system, via Lewis-type antigens expressed on MUC1. 
The importance of glycans in human milk is stressed by studies showing strong inverse correlations between the incidence of diarrhea caused by different pathogens such as Campylobacter, Norovirus, and Calicivirus, and the levels and types of human milk oligosaccharides $(7,8)$. In particular, 2-linked fucoses seemed responsible for the protection. Although these studies focused on oligosaccharides, our data indicate the importance of fucose moieties on glycoproteins as MUC1 as well. Furthermore, we corroborate an earlier extensive glycan analysis on human milkderived MUC1 revealing the presence of terminal fucoses (43). Interestingly, such fucoses are not expressed in bovine milk (44), confirming our data that bovine milk does not bind DC-SIGN, and may therefore not have similar pathogen inhibitory mechanisms as human milk. The high variability of fucoses in human milk depends on the genetically determined FUT2 expression of the mother. Failure to express this enzyme results in the inability to attach 2-linked fucoses during the glycosylation process. Besides inter-individual variability, secretion of the fucosylated glycans also shows large variations during the course of lactation (40). In addition to the relationship with diarrhea, it would be highly interesting to study whether these individual variations affects the development of the immune system and the immunological outcome later in life.

At present, we have only begun to realize the importance of our gastrointestinal tract in shaping the immune system. Understanding the immunological benefits of human milk compounds is highly valuable in order to stimulate proper development of the infant's immune system. Additionally, infant formulas could be supplemented with glycosylated compounds based on human milk, aiming to provide the same beneficial effects. Most favorable, specific human milk compounds may be used to influence the development of the infant's immune system in such a way that allergies and autoimmune diseases later in life will be reduced or even eliminated.

\section{ACKNOWLEDGMENTS}

This work was supported by a grant from Top Institute Pharma, T1-214.

\section{REFERENCES}

1. Verhasselt V. Neonatal tolerance under breastfeeding influence. Curr Opin Immunol (2010) 22:623-30. doi:10.1016/j.coi.2010.08.008

2. Le Huërou-Luron I, Blat S, Boudry G. Breast- v. formula-feeding: impacts on the digestive tract and immediate and long-term health effects. Nutr Res Rev (2010) 23:23-36. doi:10.1017/S0954422410000065

3. Rigas A, Rigas B, Glassman M, Yen YY, Lan SJ, Petridou E, et al. Breast-feeding and maternal smoking in the etiology of Crohn's disease and ulcerative colitis in childhood. Ann Epidemiol (1993) 3:387-92. doi:10.1016/1047-2797(93) 90066-D

4. Mason T, Rabinovich CE, Fredrickson DD, Amoroso K, Reed AM, Stein LD, et al. Breast feeding and the development of juvenile rheumatoid arthritis. J Rheumatol (1995) 22:1166-70.

5. Farnaud S, Evans RW. Lactoferrin - a multifunctional protein with antimicrobial properties. Mol Immunol (2003) 40:395-405. doi:10.1016/S0161-5890(03) 00152-4

6. Masschalck B, Michiels CW. Antimicrobial properties of lysozyme in relation to foodborne vegetative bacteria. Crit Rev Microbiol (2003) 29:191-214. doi:10.1080/713610448

7. Morrow AL, Ruiz-Palacios GM, Altaye M, Jiang X, Guerrero ML, Meinzen-Derr $\mathrm{JK}$, et al. Human milk oligosaccharides are associated with protection against diarrhea in breast-fed infants. JPediatr (2004) 145:297-303. doi:10.1016/j.jpeds. 2004.04.054

8. Newburg DS, Ruiz-Palacios GM, Altaye M, Chaturvedi P, Meinzen-Derr J, Guerrero Mde L, et al. Innate protection conferred by fucosylated oligosaccharides of human milk against diarrhea in breastfed infants. Glycobiology (2004) 14:253-63. doi:10.1093/glycob/cwh020

9. Stepans MB, Wilhelm SL, Hertzog M, Rodehorst TK, Blaney S, Clemens B, et al. Early consumption of human milk oligosaccharides is inversely related to subsequent risk of respiratory and enteric disease in infants. Breastfeed Med (2006) 1:207-15. doi:10.1089/bfm.2006.1.207

10. Engering A, Geijtenbeek TB, van Vliet SJ, Wijers M, van Liempt E, Demau$\operatorname{rex} \mathrm{N}$, et al. The dendritic cell-specific adhesion receptor DC-SIGN internalizes antigen for presentation to T cells. J Immunol (2002) 168:2118-26. doi:10.4049/jimmunol.168.5.2118

11. Tacken PJ, de Vries IJ, Gijzen K, Joosten B, Wu D, Rother RP, et al. Effective induction of naive and recall $\mathrm{T}$-cell responses by targeting antigen to human dendritic cells via a humanized anti-DC-SIGN antibody. Blood (2005) 106:1278-85. doi:10.1182/blood-2005-01-0318

12. Singh SK, Stephani J, Schaefer M, Kalay H, García-Vallejo JJ, den Haan J, et al. Targeting glycan modified OVA to murine DC-SIGN transgenic dendritic cells enhances MHC class I and II presentation. Mol Immunol (2009) 47:164-74. doi:10.1016/j.molimm.2009.09.026

13. Unger WW, van Beelen AJ, Bruijns SC, Joshi M, Fehres CM, van Bloois L, et al. Glycan-modified liposomes boost CD4+ and CD8+ T-cell responses by targeting DC-SIGN on dendritic cells. J Control Release (2012) 160:88-95. doi:10.1016/j.jconrel.2012.02.007

14. Gringhuis SI, den Dunnen J, Litjens M, van Het Hof B, van Kooyk Y, Geijtenbeek TB. C-type lectin DC-SIGN modulates toll-like receptor signaling via Raf1 kinase-dependent acetylation of transcription factor NF-kappaB. Immunity (2007) 26:605-16. doi:10.1016/j.immuni.2007.03.012

15. Hovius JW, de Jong MA, den Dunnen J, Litjens M, Fikrig E, van der Poll T, et al. Salp15 binding to DC-SIGN inhibits cytokine expression by impairing both nucleosome remodeling and mRNA stabilization. PLoS Pathog (2008) 4:e31. doi:10.1371/journal.ppat.0040031

16. Hodges A, Sharrocks K, Edelmann M, Baban D, Moris A, Schwartz O, et al. Activation of the lectin DC-SIGN induces an immature dendritic cell phenotype triggering Rho-GTPase activity required for HIV-1 replication. Nat Immunol (2007) 8:569-77. doi:10.1038/ni1470

17. Bergman MP, Engering A, Smits HH, van Vliet SJ, van Bodegraven AA, Wirth HP, et al. Helicobacter pylori modulates the Thelper cell $1 /$ T helper cell 2 balance through phase-variable interaction between lipopolysaccharide and DC-SIGN. J Exp Med (2004) 200:979-90. doi:10.1084/jem.20041061

18. Smits HH, Engering A, van der Kleij D, de Jong EC, Schipper K, van Capel TM, et al. Selective probiotic bacteria induce IL-10-producing regulatory $\mathrm{T}$ cells in vitro by modulating dendritic cell function through dendritic cell-specific intercellular adhesion molecule 3-grabbing nonintegrin. J Allergy Clin Immunol (2005) 115:1260-7. doi:10.1016/j.jaci.2005.03.036

19. van Vliet SJ, Garcia-Vallejo JJ, van KY. Dendritic cells and C-type lectin receptors: coupling innate to adaptive immune responses. Immunol Cell Biol (2008) 86:580-7. doi:10.1038/icb.2008.55

20. Garcia-Vallejo JJ, van KY. Endogenous ligands for C-type lectin receptors: the true regulators of immune homeostasis. Immunol Rev (2009) 230:22-37. doi:10.1111/j.1600-065X.2009.00786.x

21. Hooper LV, Littman DR, Macpherson AJ. Interactions between the microbiota and the immune system. Science (2012) 336:1268-73. doi:10.1126/science. 1223490

22. te Velde AA, van Kooyk Y, Braat H, Hommes DW, Dellemijn TA, Slors JF, et al. Increased expression of DC-SIGN+IL-12+IL-18+ and CD83+IL-12-IL-18- dendritic cell populations in the colonic mucosa of patients with Crohn's disease. Eur J Immunol (2003) 33:143-51. doi:10.1002/immu.200390017

23. Figdor CG, van KY, Adema GJ. C-type lectin receptors on dendritic cells and Langerhans cells. Nat Rev Immunol (2002) 2:77-84. doi:10.1038/nri827

24. Appelmelk BJ, van Die I, van Vliet SJ, Vandenbroucke-Grauls CM, Geijtenbeek TB, van Kooyk Y. Cutting edge: carbohydrate profiling identifies new pathogens that interact with dendritic cell-specific ICAM-3-grabbing nonintegrin on dendritic cells. J Immunol (2003) 170:1635-9. doi:10.4049/jimmunol.170.4.1635

25. van Vliet SJ, Steeghs L, Bruijns SC, Vaezirad MM, Snijders Blok C, Arenas Busto JA, et al. Variation of Neisseria gonorrhoeae lipooligosaccharide directs 
dendritic cell-induced T helper responses. PLoS Pathog (2009) 5:e1000625. doi:10.1371/journal.ppat.1000625

26. García-Vallejo JJ, Van Het Hof B, Robben J, Van Wijk JA, Van Die I, Joziasse $\mathrm{DH}$, et al. Approach for defining endogenous reference genes in gene expression experiments. Anal Biochem (2004) 329:293-9. doi:10.1016/j.ab.2004. 02.037

27. Rescigno M, Urbano M, Valzasina B, Francolini M, Rotta G, Bonasio R, et al. Dendritic cells express tight junction proteins and penetrate gut epithelial monolayers to sample bacteria. Nat Immunol (2001) 2:361-7. doi:10.1038/86373

28. Bogunovic M, Ginhoux F, Helft J, Shang L, Hashimoto D, Greter M, et al. Origin of the lamina propria dendritic cell network. Immunity (2009) 31:513-25. doi:10.1016/j.immuni.2009.08.010

29. Soilleux EJ, Morris LS, Leslie G, Chehimi J, Luo Q, Levroney E, et al. Constitutive and induced expression of DC-SIGN on dendritic cell and macrophage subpopulations in situ and in vitro. J Leukoc Biol (2002) 71:445-57.

30. Mosconi E, Rekima A, Seitz-Polski B, Kanda A, Fleury S, Tissandie E, et al. Breast milk immune complexes are potent inducers of oral tolerance in neonates and prevent asthma development. Mucosal Immunol (2010) 3:461-74. doi:10.1038/mi.2010.23

31. Verhasselt V, Milcent V, Cazareth J, Kanda A, Fleury S, Dombrowicz $\mathrm{D}$, et al. Breast milk-mediated transfer of an antigen induces tolerance and protection from allergic asthma. Nat Med (2008) 14:170-5. doi:10.1038/ nm1718

32. Verhasselt $\mathrm{V}$. Neonatal tolerance under breastfeeding influence: the presence of allergen and transforming growth factor-beta in breast milk protects the progeny from allergic asthma. J Pediatr (2010) 156:S16-20. doi:10.1016/j.jpeds.2009. 11.015

33. Zhou Y, Kawasaki H, Hsu SC, Lee RT, Yao X, Plunkett B, et al. Oral tolerance to food-induced systemic anaphylaxis mediated by the C-type lectin SIGNR1. Nat Med (2010) 16:1128-33. doi:10.1038/nm.2201

34. Goldman AS. The immune system of human milk: antimicrobial, antiinflammatory and immunomodulating properties. Pediatr Infect Dis J (1993) 12:664-71. doi:10.1097/00006454-199308000-00008

35. Naarding MA, Ludwig IS, Groot F, Berkhout B, Geijtenbeek TB, Pollakis G, et al. Lewis X component in human milk binds DC-SIGN and inhibits HIV-1 transfer to CD4+ T lymphocytes. J Clin Invest (2005) 115:3256-64. doi:10.1172/JCI25105

36. Hong P, Ninonuevo MR, Lee B, Lebrilla C, Bode L. Human milk oligosaccharides reduce HIV-1-gp120 binding to dendritic cell-specific ICAM3grabbing non-integrin (DC-SIGN). Br J Nutr (2009) 101:482-6. doi:10.1017/ S0007114508025804

37. Saeland E, de Jong MA, Nabatov AA, Kalay H, Geijtenbeek TB, van Kooyk Y. MUC1 in human milk blocks transmission of human immunodeficiency virus from dendritic cells to T cells. Mol Immunol (2009) 46:2309-16. doi:10.1016/j. molimm.2009.03.025
38. Stromqvist M, Falk P, Bergstrom S, Hansson L, Lönnerdal B, Normark S, et al. Human milk kappa-casein and inhibition of Helicobacter pylori adhesion to human gastric mucosa. J Pediatr Gastroenterol Nutr (1995) 21:288-96. doi:10.1097/00005176-199510000-00006

39. Aniansson G, Andersson B, Lindstedt R, Svanborg C. Anti-adhesive activity of human casein against Streptococcus pneumoniae and Haemophilus influenzae. Microb Pathog (1990) 8:315-23. doi:10.1016/0882-4010(90)90090-D

40. Ruvoën-Clouet N, Mas E, Marionneau S, Guillon P, Lombardo D, Le Pendu J. Bile-salt-stimulated lipase and mucins from milk of 'secretor' mothers inhibit the binding of Norwalk virus capsids to their carbohydrate ligands. Biochem $J$ (2006) 393:627-34. doi:10.1042/BJ20050898

41. Labéta MO, Vidal K, Nores JE, Arias M, Vita N, Morgan BP, et al. Innate recognition of bacteria in human milk is mediated by a milk-derived highly expressed pattern recognition receptor, soluble CD14. J Exp Med (2000) 191:1807-12. doi:10.1084/jem.191.10.1807

42. Lilius EM, Marnila P. The role of colostral antibodies in prevention of microbial infections. Curr Opin Infect Dis (2001) 14:295-300. doi:10.1097/00001432200106000-00008

43. Parry S, Hanisch FG, Leir SH, Sutton-Smith M, Morris HR, Dell A, et al. NGlycosylation of the MUC1 mucin in epithelial cells and secretions. Glycobiology (2006) 16:623-34. doi:10.1093/glycob/cwj110

44. Wilson NL, Robinson LJ, Donnet A, Bovetto L, Packer NH, Karlsson NG. Glycoproteomics of milk: differences in sugar epitopes on human and bovine milk fat globule membranes. J Proteome Res (2008) 7:3687-96. doi:10.1021/ pr700793k

Conflict of Interest Statement: The authors declare that the research was conducted in the absence of any commercial or financial relationships that could be construed as a potential conflict of interest.

Received: 27 December 2014; accepted: 26 February 2015; published online: 13 March 2015.

Citation: Koning N, Kessen SFM, Van Der Voorn JP, Appelmelk BJ, Jeurink PV, Knippels LMJ, Garssen J and Van Kooyk Y (2015) Human milk blocks DC-SIGN-pathogen interaction via MUC1. Front. Immunol. 6:112. doi 10.3389/fimmu.2015.00112

This article was submitted to Nutritional Immunology, a section of the journal Frontiers in Immunology.

Copyright $\odot 2015$ Koning, Kessen, Van Der Voorn, Appelmelk, Jeurink, Knippels, Garssen and Van Kooyk. This is an open-access article distributed under the terms of the Creative Commons Attribution License (CC BY). The use, distribution or reproduction in other forums is permitted, provided the original author(s) or licensor are credited and that the original publication in this journal is cited, in accordance with accepted academic practice. No use, distribution or reproduction is permitted which does not comply with these terms. 